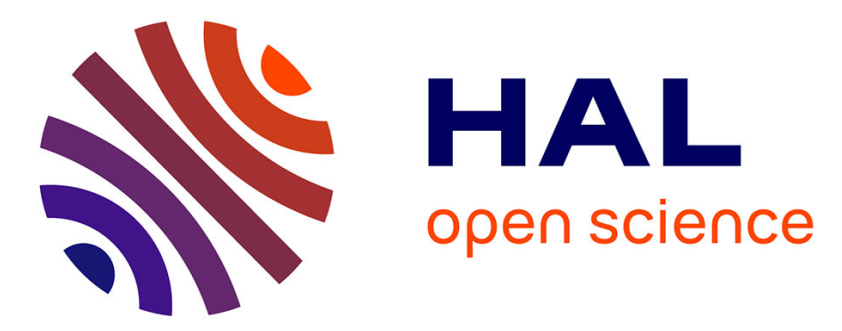

\title{
Study of secondary arcing occurrence on solar panel backside wires with cracks
}

\author{
J.M. Siguier, V. Inguimbert, Gaétan Murat, D. Payan, N. Balcon
}

\section{To cite this version:}

J.M. Siguier, V. Inguimbert, Gaétan Murat, D. Payan, N. Balcon. Study of secondary arcing occurrence on solar panel backside wires with cracks. Spacecraft Charging Technology Conference 2014 (13th SCTC), Jun 2014, PASADENA, United States. hal-01081189

\section{HAL Id: hal-01081189 \\ https://hal.science/hal-01081189}

Submitted on 7 Nov 2014

HAL is a multi-disciplinary open access archive for the deposit and dissemination of scientific research documents, whether they are published or not. The documents may come from teaching and research institutions in France or abroad, or from public or private research centers.
L'archive ouverte pluridisciplinaire HAL, est destinée au dépôt et à la diffusion de documents scientifiques de niveau recherche, publiés ou non, émanant des établissements d'enseignement et de recherche français ou étrangers, des laboratoires publics ou privés. 


\title{
Study of secondary arcing occurrence on solar panel backside wires with cracks
}

\author{
Jean-Michel Siguier, Virginie Inguimbert, Gaël Murat, Denis Payan and Nicolas Balcon
}

\begin{abstract}
Space environment exposure may create cracks on solar panel backside wires. Considering the wiring design of solar array backside, environmental constraints applied on each wire are identical. Thus, the probability of two adjacent wires to have cracks facing each other is very high. This configuration presents a risk of secondary arc occurrence which can lead to a destructive process as arc-tracking. In order to determine in which conditions electrostatic discharges (ESD) can lead to an arc, we have carried out an experimental study on solar panel backside-like samples.

We have tested different types of wires presenting artificial mechanical cracks or space simulation aging cracks, set on a solar panel backside coupon.

The wires are connected to a secondary arc test setup including a solar array simulator (SAS) set to different current values.

As both direct and inverted potential gradient (IPG) charging are theoretically possible on geostationary orbit (GEO) and low earth orbit (LEO), we have carried out, in the JONAS vacuum chamber (ONERA facility), both charging types. Direct charging was achieved with an electron gun and IPG with a plasma source.

Results are presented for the two types of charging, different types of wire, and different SAS current values. They show that, in direct charging conditions, ESD propagates along the wires but the plasma density is too weak to provoke an arc. In IPG situation, ESDs are able to trigger different arc types: nonsustain arc (NSA), temporary sustain arc (TSA) and permanent sustain arc (PSA), depending on SAS current values.
\end{abstract}

Keywords-ESD; electrostatic discharge; solar panel; arcing; secondary arc

\section{INTRODUCTION}

It is well established that aging, due to environmental and mechanical constraints, is responsible of cracks occurring on satellite cables especially on solar array backsides and harnesses [1] [2]. These cracks can be at the origin of failures and power losses when an electrostatic discharge (ESD) or primary arc) occurs in the vicinity of the cracks leading to a secondary arc short-circuiting the cables. In the continuation of previous studies [3] [4], we have carried out investigations on secondary arcing occurrence on solar array backside-like samples in different charging situations and with different solar array simulator (SAS) values.

We have considered that both direct and inverted potential gradient (IPG) charging situations are theoretically possible on geostationary orbit (GEO) and low earth orbit (LEO). Thus,

J-M Siguier, V. Inguimbert and G. Murat are with the Onera - The French Aerospace Lab, F-31055 Toulouse, France

(e-mail: jean-michel.siguier@onera.fr)

Denis Payan and Nicolas Balcon are with CNES, F-31401 Toulouse, France charging procedures were performed in order to reach the two situations.

We have selected two types of space used cables and test them in a backside-like solar array sample made with carbon fiber reinforced polymer (CFRP) on aluminum honeycomb.

The cables are connected to an electric circuit simulating a solar array power line using a SAS set to different values in order to determine secondary arc occurrence thresholds.

\section{TEST COUPON CONFIGURATION}

\section{A. Sample description}

We have tested 2 types of cable:

- Tefzel® ref. Tyco 55/9952 gauge 20 (Fig. 1 and Fig. 2)

- Kapton® ref. ESA/SCC 3901/002 gauge 20 (Fig. 3)

Cracks were made with a cutter blade on pristine cables. For Tefzel ${ }^{\circledR}$ we have also tested aged cables with space environment conditions simulation (collected on an aged coupon provided by Kitakyushu Institute of Technology) [5]. The 3 pairs of cables are fixed on a CFRP board with RTV-S691 glue (Fig. 4).

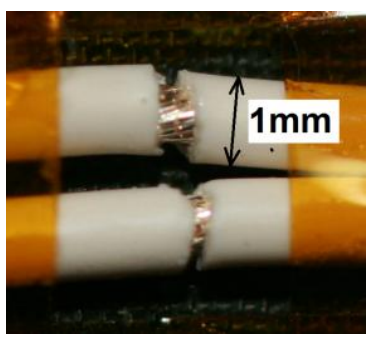

Fig. 1: pristine Tefzel® cables. Cracks are made with cutter

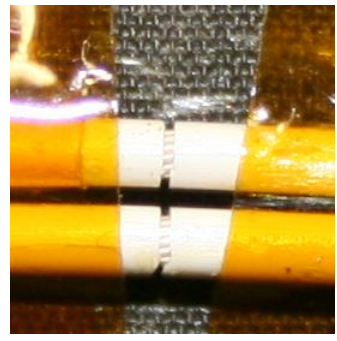

Fig. 2: aged Tefzel® cables. Cracks are due to aging

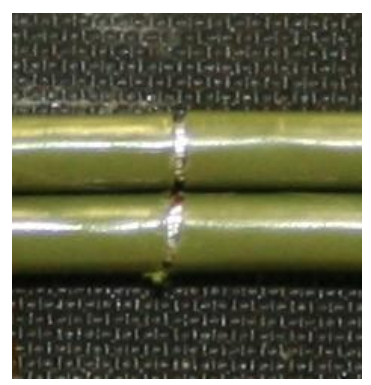

Fig. 3: pristine Kapton ${ }^{\circledR}$ cables. Cracks are made with cutter 
(Abstract No138)

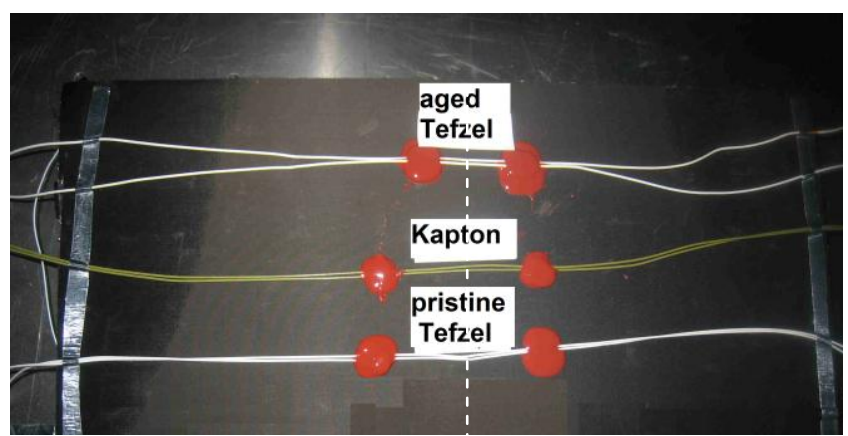

Fig. 4: cable set on CFRP board (the white dashed line shows the potential probe trajectory)

\section{B. Facility and charging conditions}

All tests were performed in the JONAS facility which is a $9 \mathrm{~m}^{3}$ vacuum chamber equipped with a plasma source (Kaufmann type), two electron guns and several measurement devices such as surface potential probe, transient current probes and CCD camera. Depending on charging conditions (IPG or direct gradient), we used either a plasma source or an electron gun.

For IPG charging, the plasma source delivers $1 \mathrm{~mA}$ current of drifting Ar+ ions accelerated to 20V. For direct charging, the electron gun provides $20 \mathrm{keV}-2 \mathrm{nA} / \mathrm{cm}^{2}$ current at the sample level (measured with Faraday cups).

\section{Electrical setup}

They are two setups depending on charging conditions (IPG or direct gradient).

1) Direct charging setup:

The electrical setup is based on arcing test of solar cell coupons (Fig. 5). The 3 pairs of cables are connected in series to maximize the probability to get a secondary arc because an ESD can occur on any pair of cables.

The honeycomb + CFRP substrate is grounded and electron flux arrives perpendicularly to it.

2) IPG charging setup:

The electrical setup is also based on arcing test of solar cell coupons (Fig. 6). The 3 pairs of cables are tested successively. Those unconnected to the SAS are connected to the honeycomb + CFRP. In order to reach IPG situation, the sample is biased to $\mathrm{HV}\left(\mathrm{V}_{\text {bias }}\right) . \mathrm{C}_{\mathrm{sat}}=300 \mathrm{pF}$ and simulates the satellite capacitance.

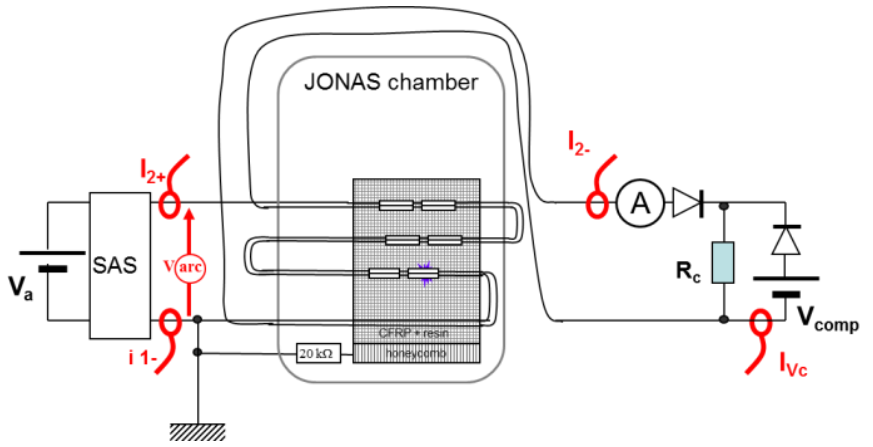

Fig. 5: electrical setup for direct charging configuration

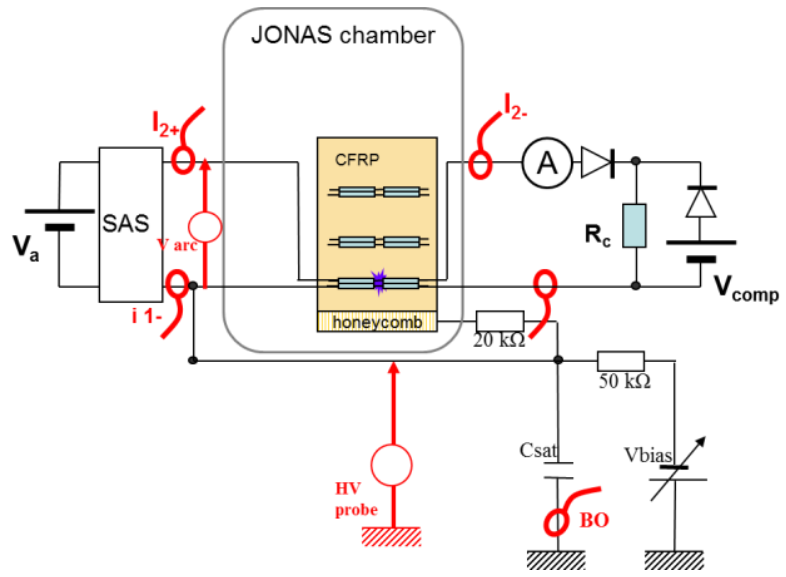

Fig. 6: electrical setup for IPG charging configuration

\section{EXPERIMENTAL RESULTS}

\section{A. Direct charging configuration}

For direct charging configuration, SAS is set to $110 \mathrm{~V}$ and the current values are increased up to $5 \mathrm{~A}$ which is the maximum we can get with our device. 1D surface potentials are measured with a non-contacting probe during charging phase and after discharges.

We have recorded about 50 discharges on different cables: about $75 \%$ are on aged Tefzel, $25 \%$ are on pristine Tefzel and none on Kapton. Fig. 7 shows an example of potential profile before and after a discharge occurring on aged Tefzel. We can notice that CFRP surface is not zero due to epoxy dielectric properties.

Because of the very small capacitance of cables, estimated to few $\mathrm{nC}$, the lightning phenomenon associated to the flashover is very weak (Fig. 8) but it proves that the flashover plasma propagates as well over the cracks.

Fig. 9 shows currents and arc voltage measured on Tefzel cable when flashover passes over the crack ( $\mathrm{V}_{\text {arc }}$ is disturbed). Nevertheless the flashover plasma is not enough dense to provoke a secondary arc when it passes over the cracks. In direct charging, there is no cathodic spot able to create this dense plasma. These results are very similar to those obtained by [4] where no secondary arc was triggered and same current shapes were recorded.

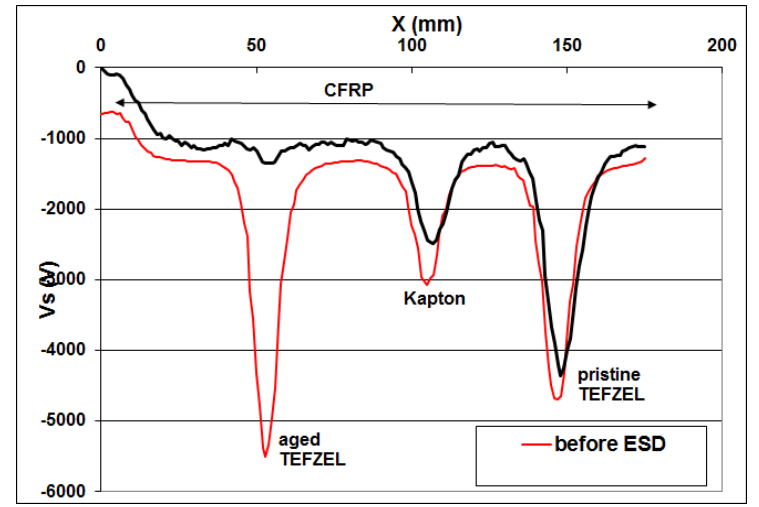

Fig. 7: Example of potential profile before and after ESD in direct charging configuration (trajectory of the probe is visible on Fig. 4) 


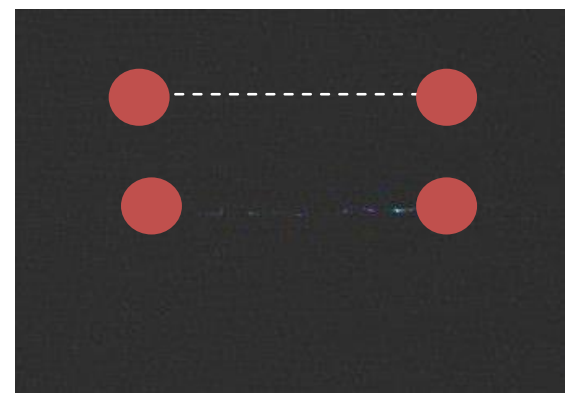

Fig. 8: Example of lightning phenomenon associated to the flashover on Tefzel cable. Approximate positions of Kapton cables (dashed line) and of RTV plots are drawn on the photograph)

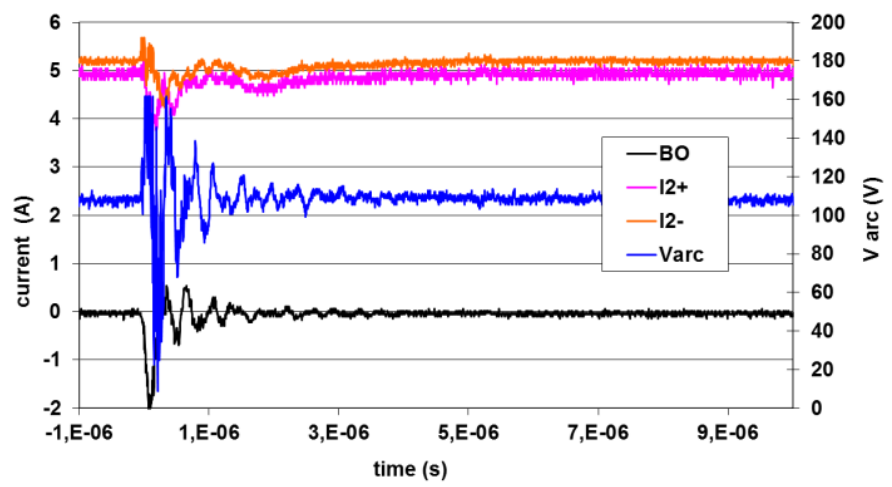

Fig. 9: Example of transient current and voltage recorded on Tefzel cable during an ESD

\section{B. IPG configuration}

For IPG configuration, SAS is set to $110 \mathrm{~V}$ and the current values are increased up to $3 \mathrm{~A}$.

$\mathrm{V}_{\text {bias }}$ is set to the minimum value corresponding to the ESD triggering threshold.

From $V_{\text {bias }}=-80 \mathrm{~V}$, many discharges (more than 10/s) occurs on the CFRP, all over the surface, because this composite presents a multitude of triple points which are the condition of IPG discharge triggering: carbon fibers are conductive and epoxy resin is dielectric in an electrostatic point of view. In the aim of limiting ESD occurrence in an area as close as possible to the cable cracks, we have covered all the CFRP surface with a Kapton film and leaved uncovered about $1 \mathrm{~cm}^{2}$ around the cable with cracks (Fig. 10).

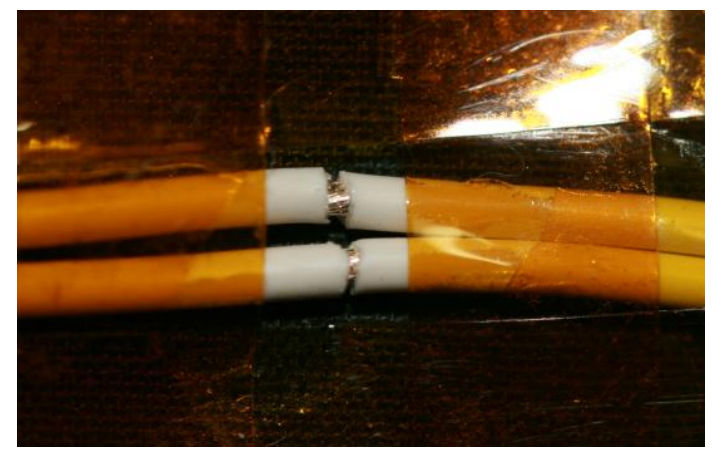

Fig. 10: Kapton film protection of substrate for IPG configuration
In this configuration, we have recorded several ESD for each SAS step. $\mathrm{V}_{\text {bias }}$ is set between $-700 \mathrm{~V}$ and $-1200 \mathrm{~V}$. All the results are summarized in TABLE 1 where arc type (NSA, TSA or PSA) and maximum arc duration are specified for each SAS step. We can see that a minimum of $2 \mathrm{~A}$ current is necessary to sustain the arc and 3A to have a permanent arc. Secondary arcing behavior between the 3 tested cables is quite similar. The fact that sometimes we do not trigger an arc with a SAS setting of $100 \mathrm{~V}-3 \mathrm{~A}$ and that we trigger only NSA with $100 \mathrm{~V}-1 \mathrm{~A}$ can be explained by a cathodic spot location on CFRP substrate too far from the crack and so not able to trigger a secondary arc. The issue of cathodic spot location has not been investigated in this study as it can also be situated at the dielectric-metal interface of the cable, which is the only possibility when the cable is set on a Kapton film substrate as it is observed on [3].

Fig. 11 is an example of currents and arc voltage measured during a TSA. Blow-off duration is always about $20 \mu \mathrm{s}$ and secondary voltage is quite stable after $50 \mu \mathrm{s}$.

TABLE 1 results can be compared with [3] where PSA is obtained at a lower SAS value $(100 \mathrm{~V}-1.3 \mathrm{~A})$ but with a larger crack (about $5 \mathrm{~mm}$ long).

Fig. 12, Fig. 13 and Fig. 14 are pictures of the cables after PSA. As we can see, the dielectric is burnt around the secondary arc location but there is no propagation of the arc, known as "arc tracking", during the few seconds of arc duration.

TABLE 1: results of arc discharge types in IPG configuration

\begin{tabular}{|c|c|c|c|}
\hline \multirow{2}{*}{ Cable type: } & \multicolumn{3}{|c|}{ SAS values: } \\
\hline & $110 \mathrm{~V}-1 \mathrm{~A}$ & $110 \mathrm{~V}-2 \mathrm{~A}$ & $110 \mathrm{~V}-3 \mathrm{~A}$ \\
\hline Aged Tefzel & $\begin{array}{l}5 \text { NSA } \\
(20 \mu \mathrm{s})\end{array}$ & $\begin{array}{l}1 \text { with no arc } \\
5 \text { NSA }(35 \mu \mathrm{s})\end{array}$ & $\begin{array}{c}10 \text { with no arc } \\
1 \text { NSA }(40 \mu \mathrm{s}) \\
2 \text { TSA }(390 \mu \mathrm{s}) \\
1 \text { PSA }\end{array}$ \\
\hline Pristine Tefzel & (not tested) & $\begin{array}{l}3 \text { with no arc } \\
1 \text { NSA }(36 \mu \mathrm{s}) \\
2 \text { TSA }(240 \mu \mathrm{s})\end{array}$ & $1 \mathrm{PSA}$ \\
\hline Kapton & (not tested) & (not tested) & $1 \mathrm{PSA}$ \\
\hline
\end{tabular}

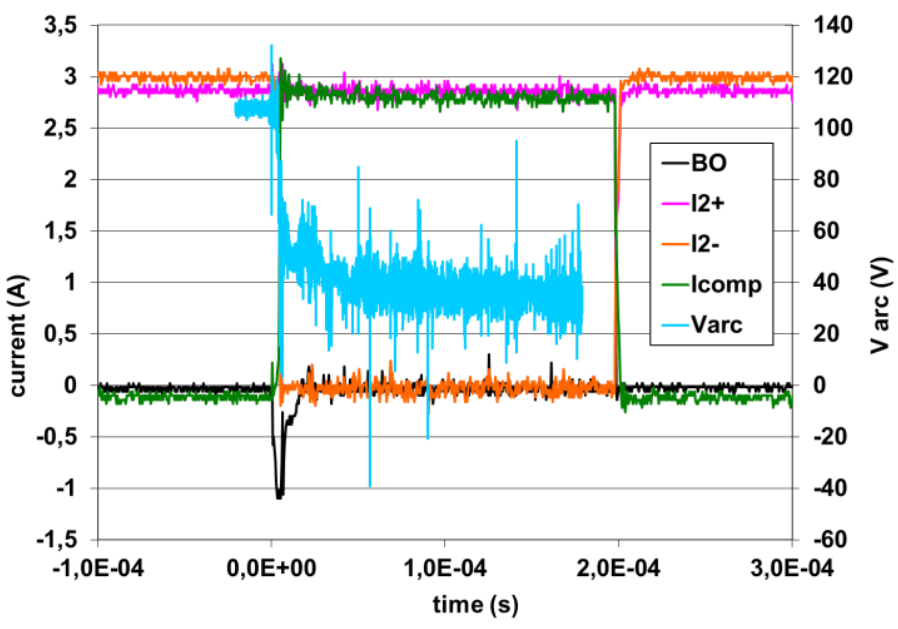

Fig. 11: example of currents and arc voltage values during a TSA on an aged Tefzel cable 


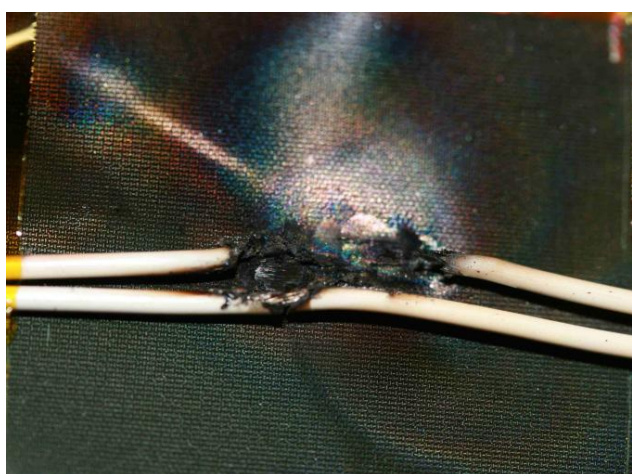

Fig. 12: pristine Tefzel cable after PSA

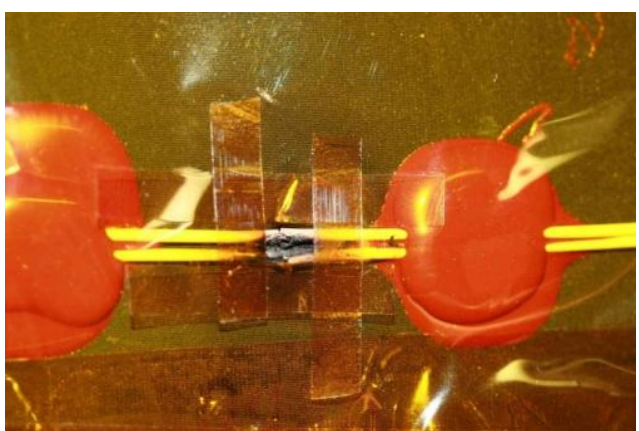

Fig. 13: aged Tefzel cable after PSA

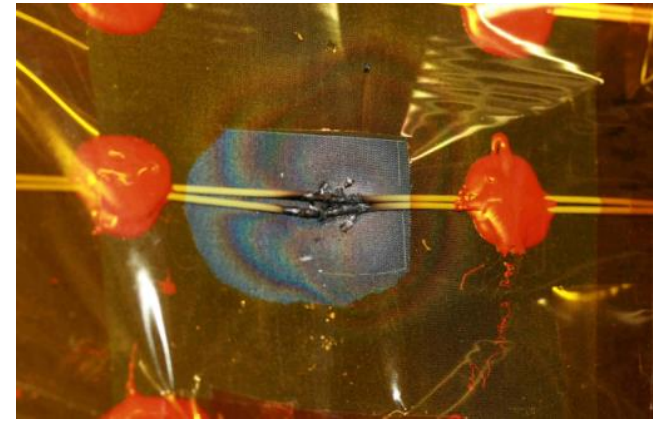

Fig. 14: Kapton cable after PSA

\section{SUMMARY}

We have studied the occurrence of primary and secondary arcs on solar array backside cables with cracks. Kapton $®$, pristine and aged Tefzel ${ }^{\circledR}$ covering cables were tested. We have investigated direct charging with high energy electrons and IPG with a plasma source. The cables under test are connected to a circuit simulating in flight conditions with a SAS set to $110 \mathrm{~V}$ and up to $3 \mathrm{~A}$.

In direct charging conditions, electrostatic discharges are produced on the cables but, due to the tenuous flashover plasma density, these primary arcs do not trigger any secondary arc.

In IPG conditions, many primary arcs occur on the CFRP substrate and maybe on the dielectric-metal interface of the cables. These ESDs trigger secondary arc of different natures depending on current values of the SAS:

- $\quad$ NSA with 1A SAS current,
- TSA with 2A SAS current,

- PSA with 3A SAS current.

No behavior difference is notice between the tested cables.

\section{ACKNOWLEDGMENT}

Thanks to B. Boulanger of Thales Alenia Space for providing Kapton ${ }^{\circledR}$ and Tefzel ${ }^{\circledR}$ cable samples and KIT (Japan) for providing aged Tefzel $®$ cable (cut on an aged solar cell coupon obtained under NEDO grant).

\section{REFERENCES}

[1] M. Bodeau, "Current and Voltage Thresholds for Sustained Arcs in Power Systems", IEEE Trans. On Plasma Science, vol. 40, n 2, pp.192200, February 2012

[2] M. Cho, "Failure Mechanisms and Protection Methods of Spacecraft Power System", Proc. of International Symposium on Electrical Insulating Materials, Kitakyushu. Japan, June 5-9, 2005

[3] D. Qu, K. Tomoki, H. Satoshi, K. Jeongho, and M. Cho, "Laboratory test of sustained arc between back surface of solar array panel and power cable", Proc. of 56th Int. Aeronautical Congress., October 2005.

[4] F. Wong, G. Gardiner, B. Hoang, T. Redick, R. Gahart, J. A. Vaughn and T. A. Schneider, "Electrostatic Discharge Tests on Solar Array, Wire coupons Subjected to Simulated Space Environment Aging", IEEE Trans on Plasma Science, vol. 40, n2, pp192, February 2012

[5] T. Endo, T. Wada, H. Masui, K. Toyoda and M. Cho, "Effect of Aging on Discharge Tolerance of Grouted Solar Array Panels Confirmed by Simulated Space Environment", 11 ${ }^{\text {th }}$ SCTC conf., Albuquerque, September 20-24, 2010 


\section{"Study of secondary arcing occurrence on solar panel backside wires with cracks"}

Jean-Michel Siguier, Virginie Inguimbert, Gaël Murat ONERA-Toulouse, France Denis Payan and Nicolas Balcon CNES-Toulouse, France
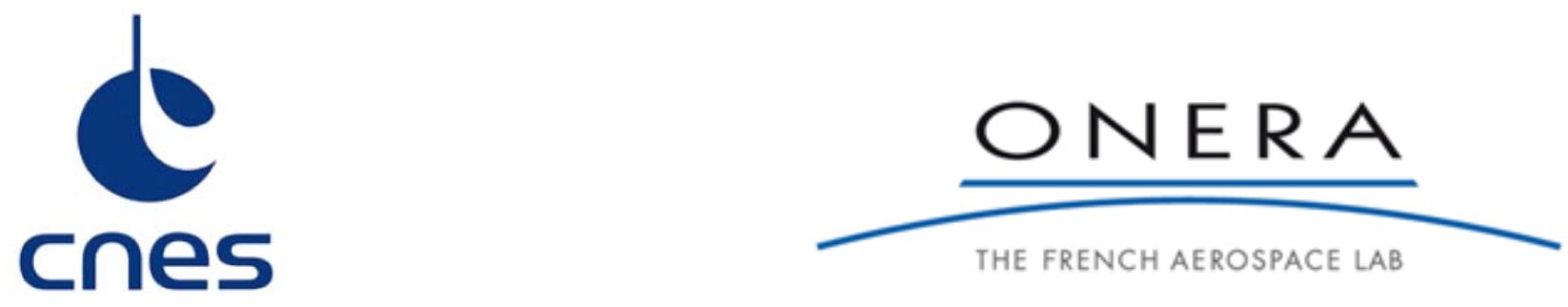


\section{History}

On October 24,2003, the power of ADEOSII suddenly decreased from $6 \mathrm{~kW}$ to $\mathrm{IkW}$ in three minutes and the satellite lost all of its function. The satellite was operated only 10 months after it was launched on December 14, 2002. It was found that the main power cables on the solar array paddle boom were burned by sustained arc.
S. Kawakita et al (2004):
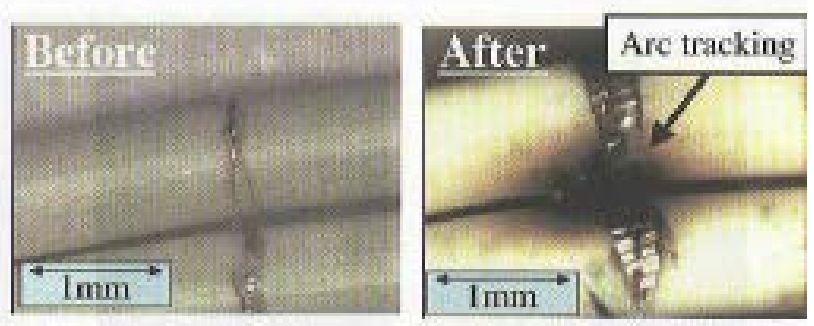

Fig. 13 The waveform of the secondary are at the temperature of $160^{\prime} \mathrm{C}$.
D. Qu et al (2005):

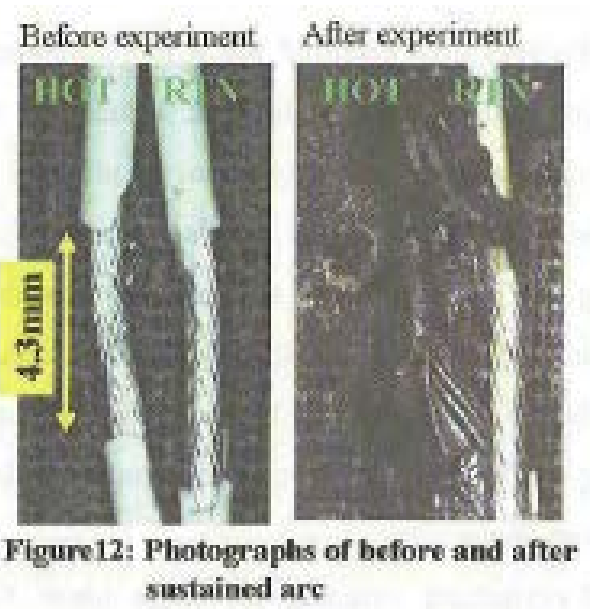

F. Wong et al (2012):

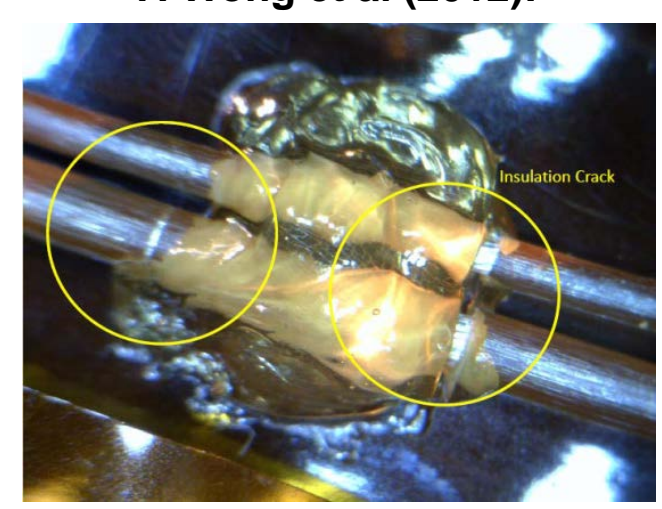




\section{Objectives of this study:}

- Which kind of charging conditions may trigger a secondary arc between two wires with defects (direct charging and Inverted Potential Gradient charging are both possible in GEO and LEO) ?

- Which SAS values (voltage/current) may trigger a secondary arc (NSA, TSA or PSA) ? 


\section{Sample description}

CFRP/honeycomb (solar array backside) RTV glue

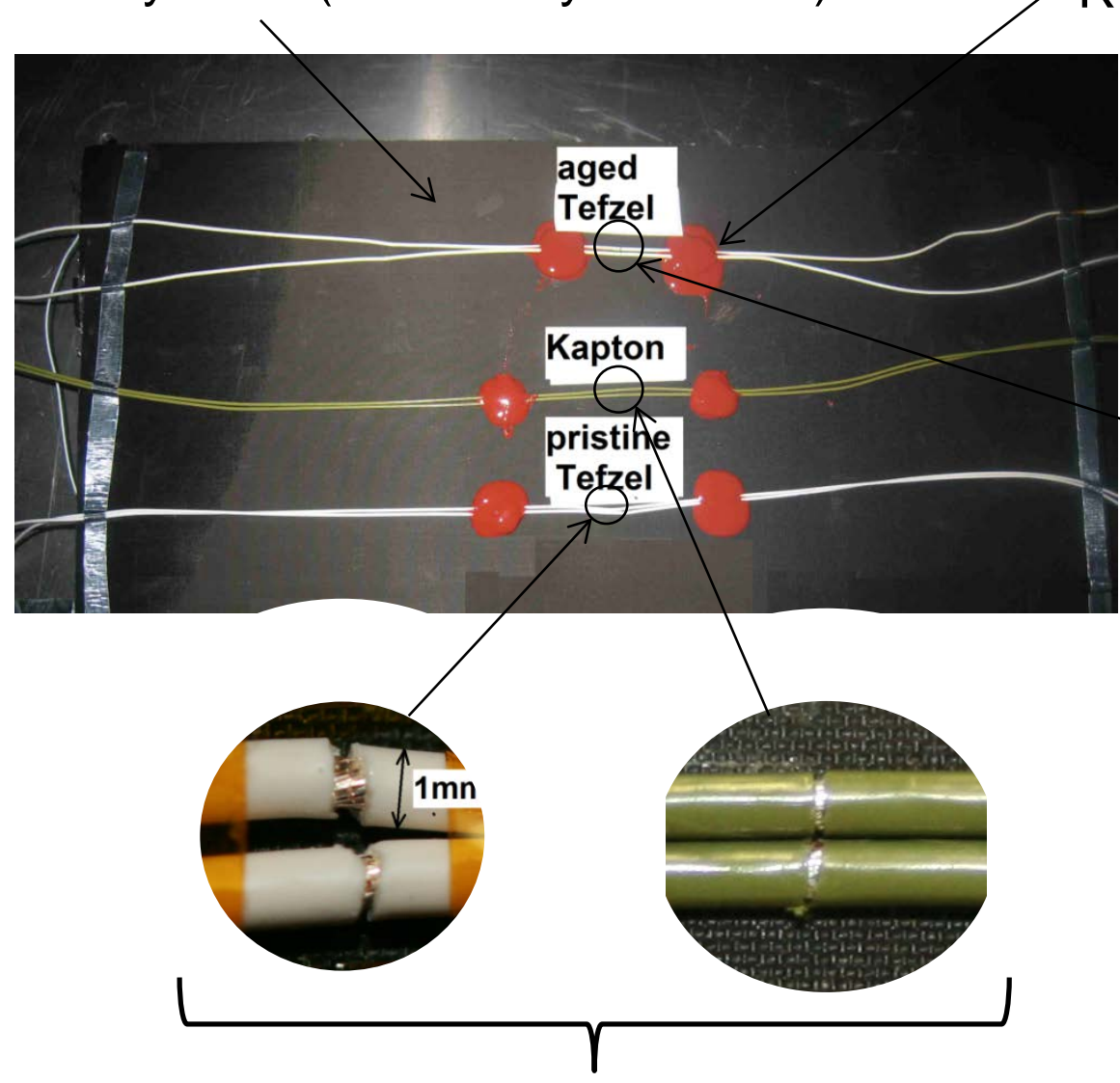

Tefzel wire:

Cracks are due to 10 years space simulation conditions aging (KIT solar cell coupon):

Cracks are made with a cutter blade 


\section{Charging conditions}

\section{Direct charging:}

High energy electrons
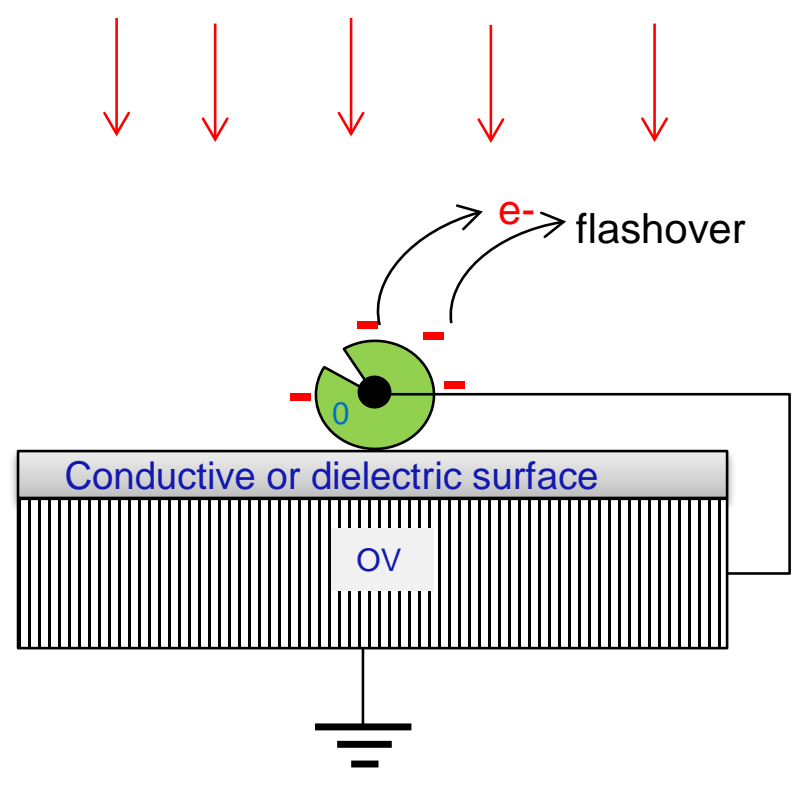

\section{Inverted Potential Gradient (IPG) charging:}
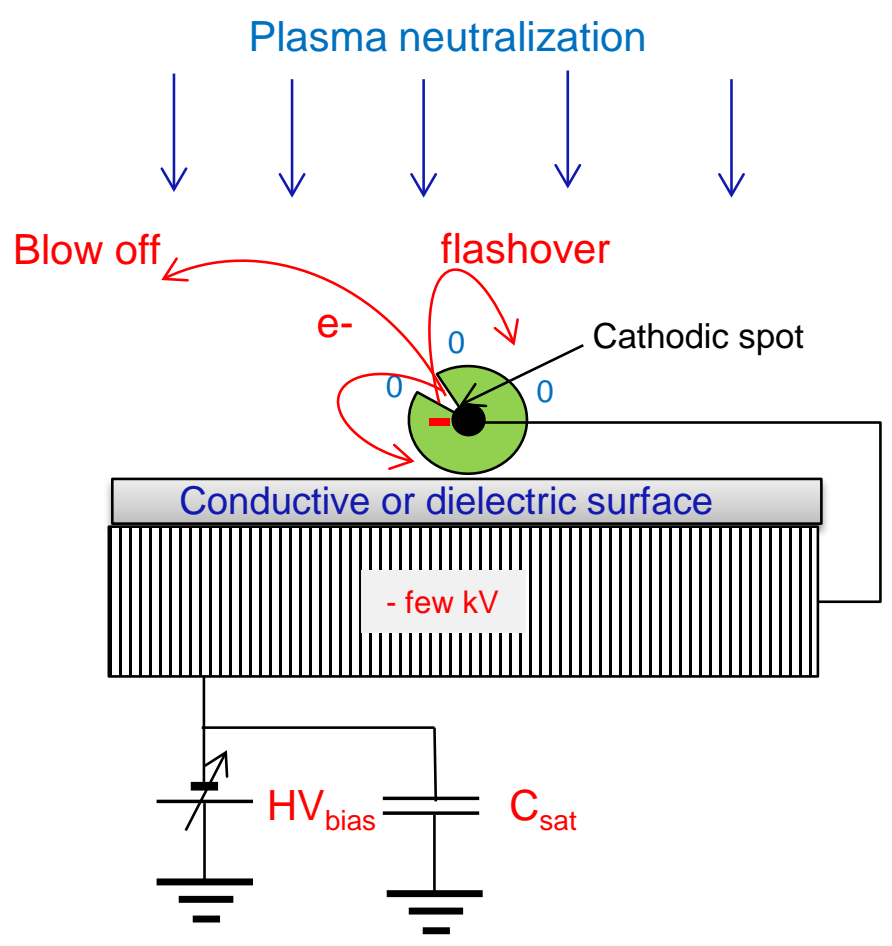


\section{Direct charging setup}

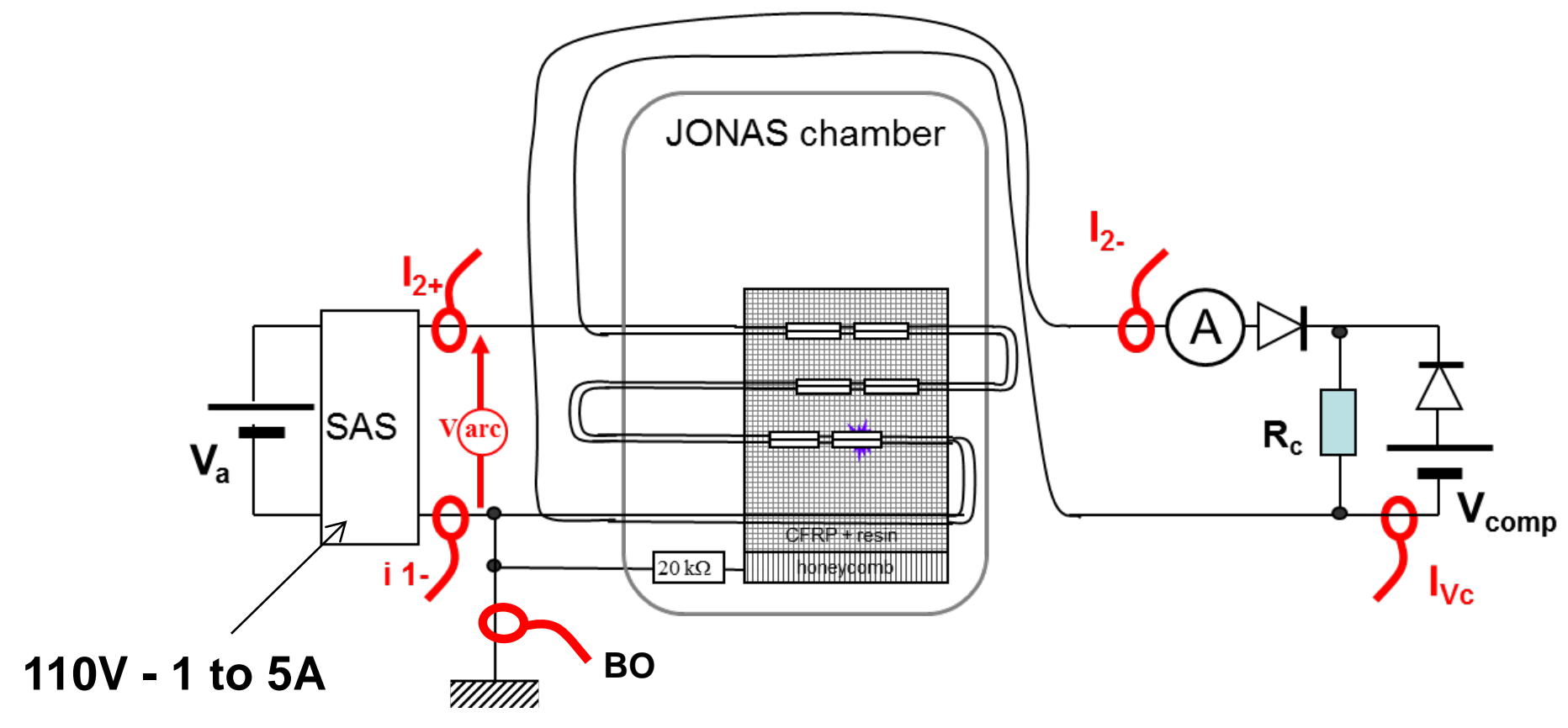




\section{Direct charging - results}

about 50 discharges on different cables:

- about $75 \%$ on aged Tefzel,

- $25 \%$ on pristine Tefzel

- none on Kapton
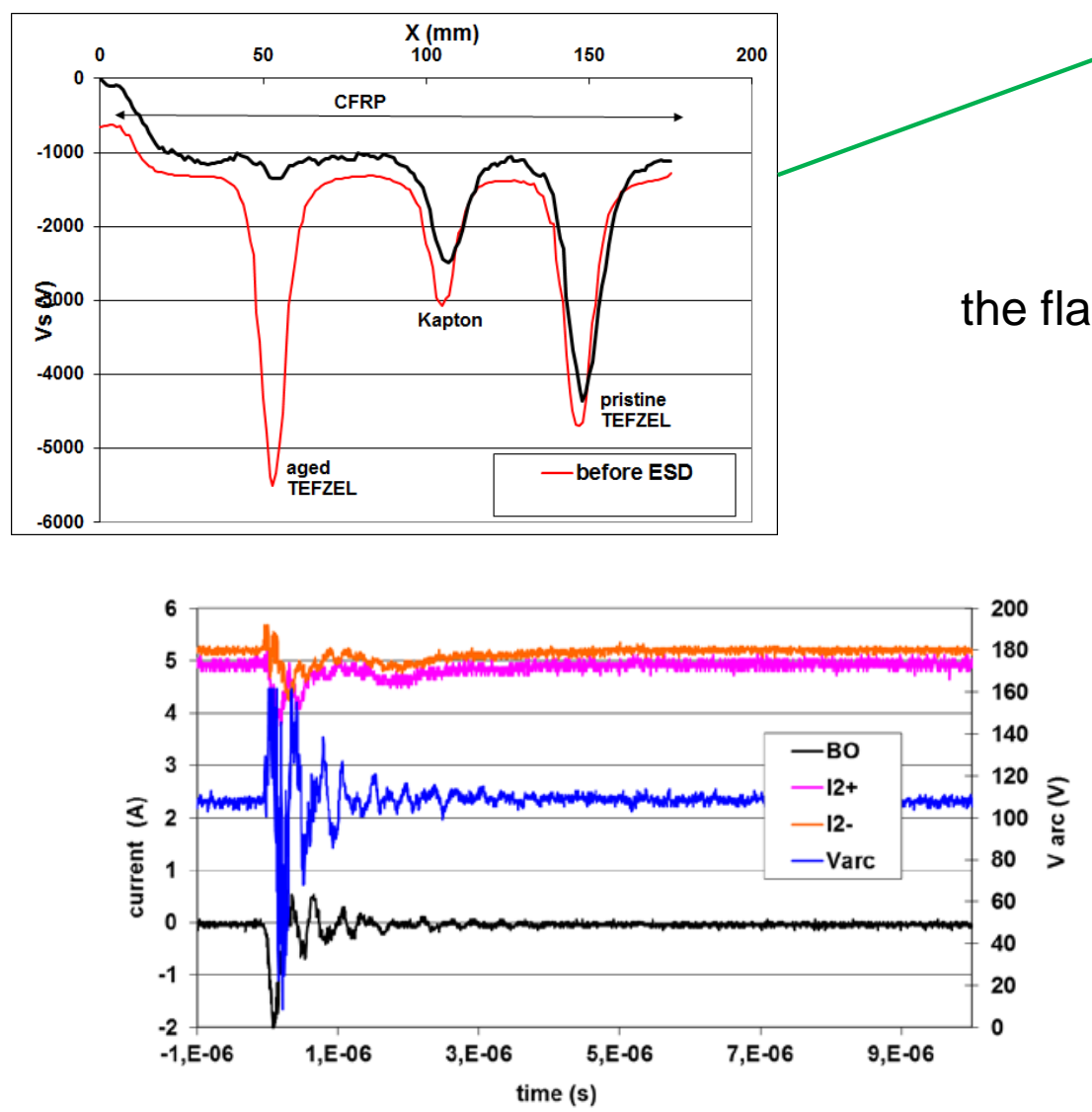

\section{pristineTefzel:}

0

Kapton:

Aged Tefzel:

the flashover plasma propagates over the cracks.

The flashover plasma is not enough dense to provoke a secondary arc when it passes over the cracks 


\section{IPG charging setup}

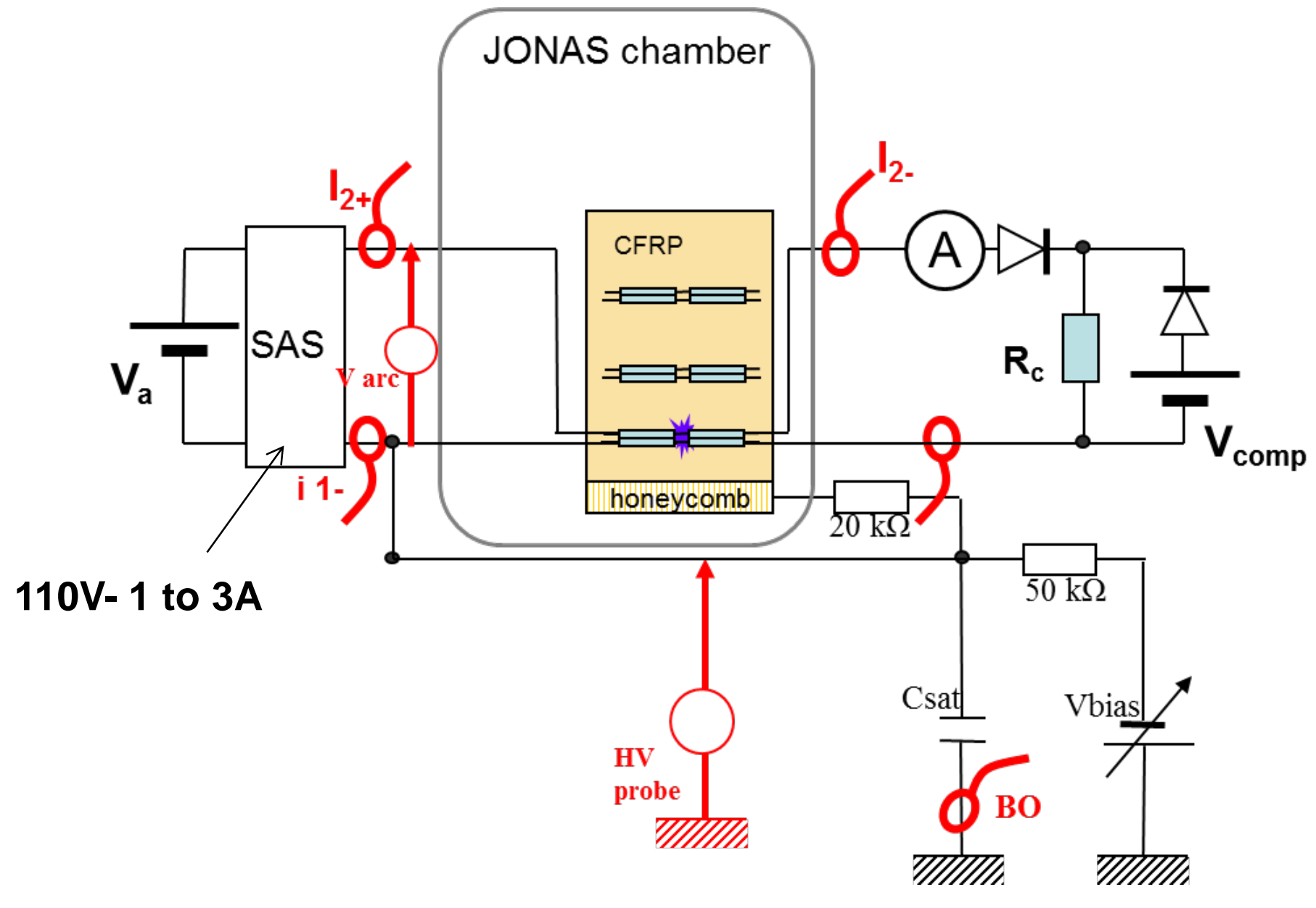




\section{Inverted Potential Gradient charging- Results (1)}

\section{Many discharges on CFRP}

CFRF $=$ carbon fiber +epoxy glue

conductive

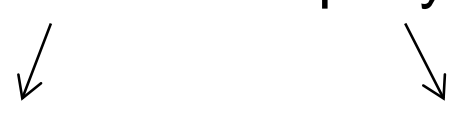

dielectric

Many triple points

(metal/dielectic/vacuum)

Requirement to trigger a secondary arc: primary arc close to the crack

CFPR covered with Kapton film

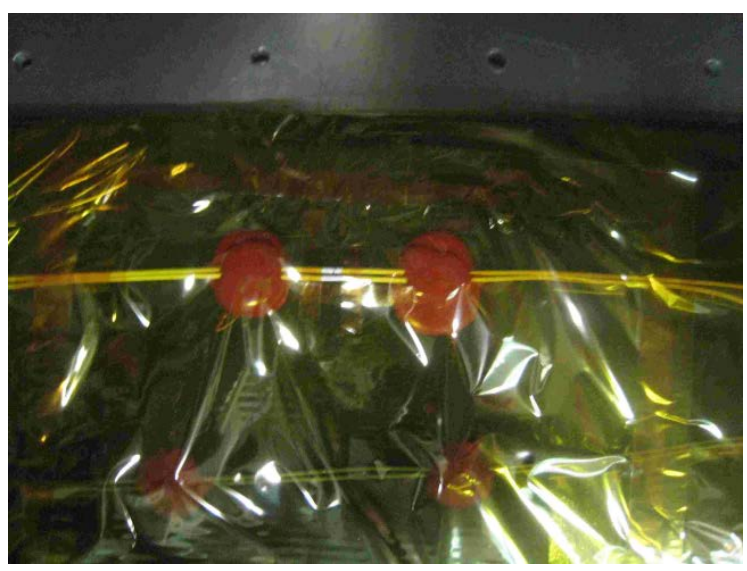

Except:

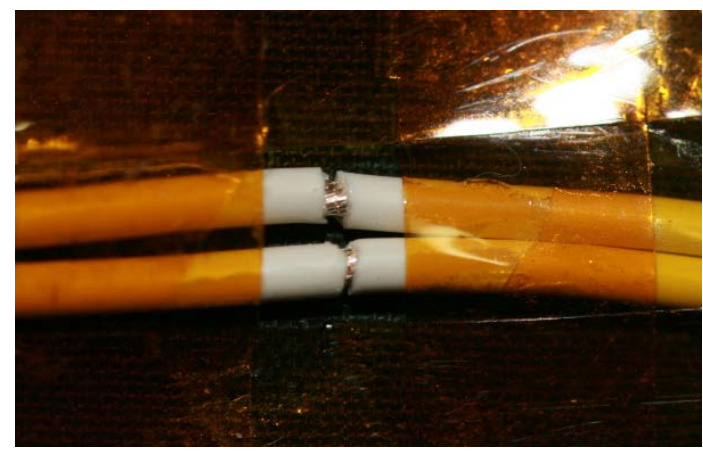




\section{Inverted Potential Gradient charging-Results}

Results of arc discharge types in IPG configuration:

The primary arc triggers a secondary arc :

\begin{tabular}{|c|c|c|c|}
\hline \multirow{2}{*}{ Cable type: } & \multicolumn{3}{|c|}{ SAS values: } \\
\hline & $110 \mathrm{~V}-1 \mathrm{~A}$ & $110 \mathrm{~V}-2 \mathrm{~A}$ & 110V-3A \\
\hline Aged Tefzel & 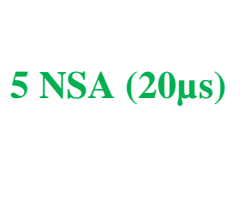 & 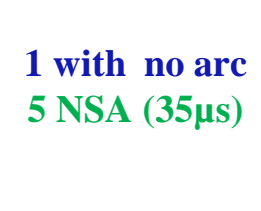 & 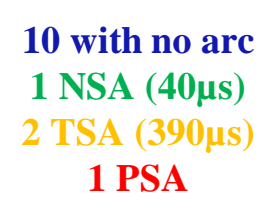 \\
\hline Pristine Tefzel & (not tested) & 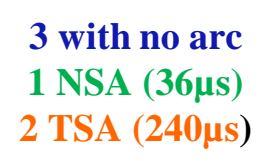 & 1 PSA \\
\hline Kapton & (not tested) & (not tested) & 1 PSA \\
\hline
\end{tabular}




\section{Inverted Potential Gradient charging- Results (3)}

Example of current and arc voltage values during a TSA:

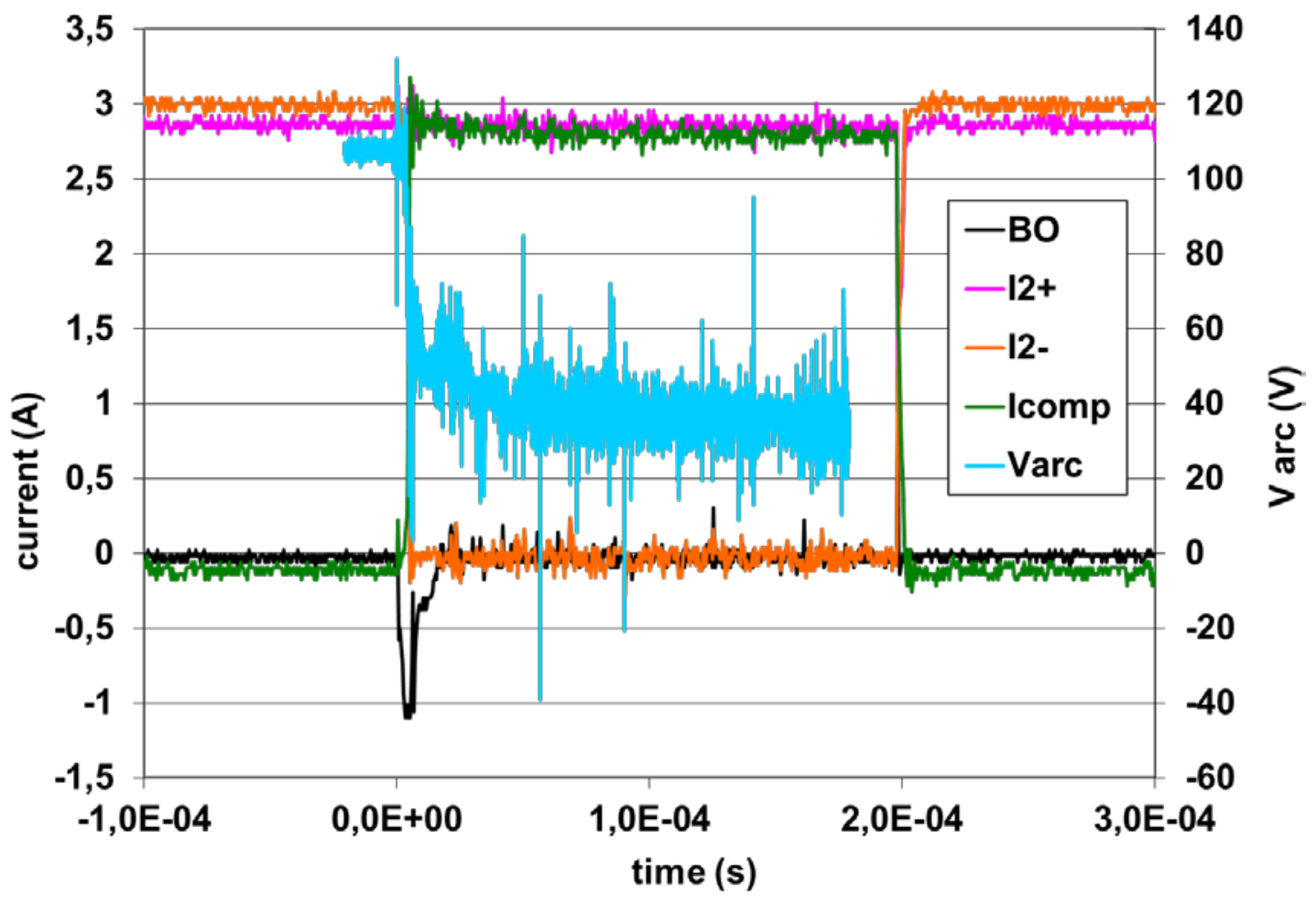


Picture of cables after PSA:

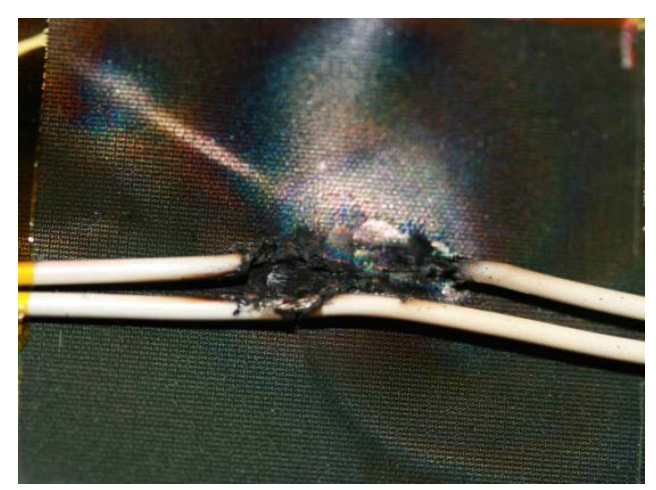

pristine Tefzel

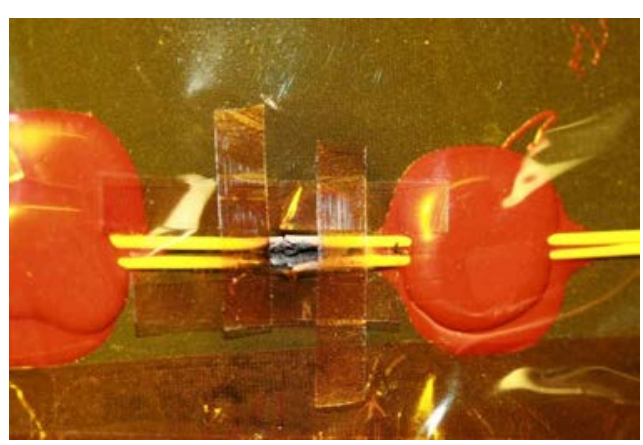

Aged Tefzel

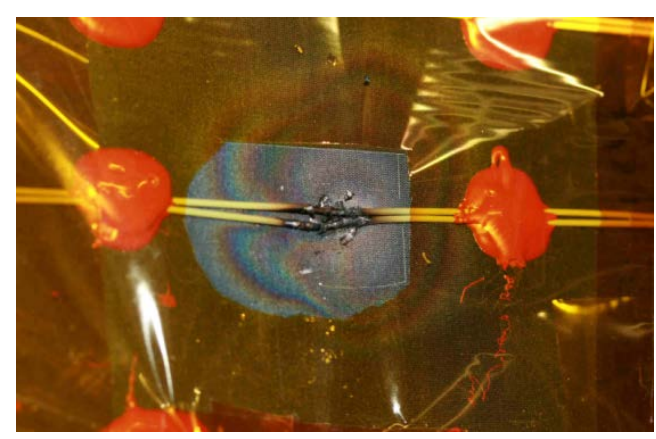

Kapton 


\section{Summary}

-We have studied the occurrence of primary and secondary arcs on solar array backside cables with cracks.

-Kapton®, pristine and aged Tefzel ${ }^{\circledR}$ covering cables were tested.

-We have investigated direct charging with high energy electrons and IPG with a plasma source. The cables under test are connected to a circuit simulating in flight conditions with a SAS set to $110 \mathrm{~V}$ and up to $5 \mathrm{~A}$.

\section{In direct charging conditions :}

Electrostatic discharges are produced on the cables but, due to the tenuous flashover plasma density, these primary arcs do not trigger any secondary arc.

\section{In IPG conditions:}

Many primary arcs occur on the CFRP substrate and maybe on the dielectric-metal interface of the cables.

These discharges trigger secondary arc for SAS values:

- NSA with SAS=110V-1A,

- TSA with SAS=110V-2A

- PSA with SAS=110V-3A 